\title{
Long-term changes of meteorological conditions of urban heat island development in the region of Debrecen, Hungary
}

\author{
Elemér László • Zsolt Bottyán • Sándor Szegedi
}

Received: 31 October 2014 / Accepted: 26 February 2015

(C) Springer-Verlag Wien 2015

\begin{abstract}
Meteorological conditions have a remarkable impact on urban climate similarly to other local and microscale climates. Clear skies and calm weather are advantageous for the development of the urban heat island (UHI). There are numerous studies on the spatial and temporal features of the phenomenon. Much less attention is paid, however, to the meteorological conditions of UHI development. The aim of the present paper is to reveal the characteristics of the changes in the frequencies of advantageous and disadvantageous meteorological conditions for UHI development on the basis of a 50 -year-long time series. Meteorological condition categories of UHI development have been established on the basis of wind speed values, cloudiness, and precipitation ranging from advantageous to disadvantageous conditions. Frequencies of occurrence of condition categories of UHI development were determined first. Advantageous and moderately advantageous conditions were found to be dominant in the time series. Linear trend analysis revealed a significant increasing trend in the time series of advantageous conditions. Increase of the frequencies of advantageous conditions was analyzed for the years, seasons, and months of the study period as well. Spring and summer (April and June) produced significant increasing trends of frequencies of advantageous conditions, while winter (with the exception of February) and autumn did not show significant increase of those frequencies. Change-point analyses detected a significant increase in the frequency of advantageous conditions in the time series at the turn of 1981/1982 especially in the summer and spring months. Detected tendencies have negative effects on urban energy consumption: they
\end{abstract}

The publication is supported by the TÁMOP-4.2.2.A-11/1/KONV-20120041 project.

E. László $(\bowtie) \cdot Z$. Bottyán $\cdot S$. Szegedi

Department of Meteorology, University of Debrecen, Egyetem tér 1, 4032 Debrecen, Hungary

e-mail: laszloelemer@gmail.com contribute to the increase of air conditioning energy demand in the summer and do not decrease the energy demand of heating in the winter significantly.

\section{Introduction}

Urban heat island (UHI) is a well-documented meso- $\gamma$ scale atmospheric phenomenon according to Orlanski's classification (Orlanski 1975; Oke 1973). UHI examinations are not homogeneous in time and space; results are not comparable due to different methods and techniques in many cases. Most studies cover short periods of time (Klysik and Fortuniak 1999), and deal with detecting the phenomenon itself or trace its relationship to other parameters (meteorological elements, static factors) (Eliasson and Svensson 2003; Szymanowski 2005). London is among the few exceptions (Wilby 2003, 2008), where connections between urban climate and urbanization process were analyzed on a long time series (Eliasson 1996; Unger et al. 2000; Loughner et al. 2012). There are hardly any long UHI measurement data sets available for the Carpathian Basin; therefore, the effects of urbanization on increasing UHI intensities cannot be traced by empirical examinations. Therefore, most studies focus on monitoring, statistical and/or numerical modeling (Arnfield 2003) of the phenomenon in our region (Bottyán and Unger 2003; Bottyán et al. 2005; Chen et al. 2011; Giannaros et al. 2013).

The thermal difference between the settlement centers and their less built-up environment is called UHI intensity. Potential maximal UHI intensities are determined by morphology (size, structure, and surface geometry) of settlements, whereas actual intensities at a given time are formed by dynamic meteorological factors embedded into synoptic conditions (Unger 1996; Unger et al. 2004; Szegedi et al. 2013). Strong heat islands can develop under anticyclone conditions 
with clear skies and calm weather without precipitation, while cyclone conditions allow the development of weak heat islands only or even prevent their formation.

The aim of our study is to reveal the changes in the frequency of advantageous and disadvantageous meteorological conditions for the development of UHI on the basis of a 50year time series for the years, their seasons, and months. According to the hypothesis of the study, there is an increasing frequency of synoptic conditions advantageous for UHI development. This can contribute to the increase of heating in winter and increase of air conditioning energy demand in summer.

\section{Materials and methods}

\subsection{Location}

Debrecen $\left(47.5^{\circ} \mathrm{N}, 21.5^{\circ} \mathrm{E}\right)$ lies at a height of $120 \mathrm{~m}$ above the sea level on the nearly flat terrain of the Great Hungarian Plain (relief is less than $20 \mathrm{~m} / 1 \mathrm{~km}$ ), which is favorable for studying the development of the urban heat island. It is the second largest city of Hungary and has a population of 204, 000. Debrecen is the cultural and economic center of the northeast region of the country (Szegedi and Kircsi 2003)

The climate of the town is moderately continental. The mean yearly temperature is $9.9^{\circ} \mathrm{C}$. Summers are hot and dry; only rainstorm and thunderstorm bring some rain. The $560-\mathrm{mm}$ mean yearly rainfall is just enough for agriculture although droughts are not rare, mainly in the Hortobágy, an area of traditional animal husbandry. The climate is pleasant, though in summer the air is dry and wind makes the heat tolerable, whereas winters are calm. The sun shines $1982 \mathrm{~h}$ on average.

\subsection{Data description}

The CarpatClim 50-year climatological time series of the Carpathian Basin was used for the analysis (Spinoni et al. 2014). It consists of diurnal datasets homogenized by the widespread multiple analysis of series for homogenization (MASH) and meteorological interpolation based on surface homogenized database (MISH) method (Lakatos et al. 2013; Szentimrey 2011; Szentimrey and Bihari 2006). The selected homogenization model depends on the distribution of the elements (Table 1). The additive model is used mostly except when precipitation or wind speed is the meteorological element. In this case, the multiplicative model is more suitable.

Datasets for the grid point 2571-which is closest to the city of Debrecen in east Hungary - were used (Fig. 1). The time series provide abundant information on air temperatures, precipitation, air pressure, wind speeds, and cloudiness.
Table 1 Set of meteorological variables in daily temporal resolution to be homogenized (JRC 2010)

\begin{tabular}{lll}
\hline Variable & Description & Units \\
\hline$T_{\mathrm{a}}$ & 2 m mean daily air temperature & ${ }^{\circ} \mathrm{C}$ \\
$T_{\min }$ & Minimum air temperature from 18:00 to 06:00 & ${ }^{\circ} \mathrm{C}$ \\
$T_{\max }$ & Maximum air temperature from 06:00 to 18:00 & ${ }^{\circ} \mathrm{C}$ \\
$p$ & Accumulated total precipitation from 06:00 to & $\mathrm{mm}$ \\
& $\quad 06: 00$ & \\
DD & 10 m wind direction & $0^{\circ}-360^{\circ}$ \\
VV & 10 m horizontal wind speed & $\mathrm{m} / \mathrm{s}$ \\
Sunshine & Sunshine duration & $\mathrm{Hours}$ \\
cc & Cloud cover & $\mathrm{Tenths}$ \\
Rglobal & Global radiation & $\mathrm{MJ} / \mathrm{m} 2$ \\
RH & Relative humidity & $\%$ \\
$P_{\text {vapour }}$ & Surface vapor pressure & $\mathrm{hPa}$ \\
Pair & Surface air pressure & $\mathrm{hPa}$ \\
\hline
\end{tabular}

Table 1 shows the set of meteorological variables in daily temporal resolution to be homogenized (http://www. carpatclim-eu.org/pages/about/).

The three most important meteorological elements from the aspect of the development of UHI are wind speed, cloudiness, and precipitation (Lee and Baik 2010). The role and weight of the obstructive factors are different (Kim and Baik 2002; Ganbat et al. 2013) since winds modify the shape of the heat island at low speeds pushing leewards the warm air formed over the city center. However, winds can eliminate the UHI over a critical wind speed characteristic for a given city size and structure. It effects mainly during the development of the UHI, while radiation conditions have strong impacts before the formation and during the development of the UHI either (Szegedi et al. 2013). Critical values of these factors, when the development of heat island becomes impossible, were determined. The thresholds were set at $3 \mathrm{~m} / \mathrm{s}$ of wind speed, 5 octas of cloudiness, and $2 \mathrm{~mm}$ of precipitation. Since results of the analyses might be influenced by the threshold values of the wind speed and cloudiness, those values were chosen based on the literature and results of our previous UHI measurement campaigns (Landsberg 1981; Oke 1987; Szegedi and Kircsi 2003; Szegedi et al. 2013) for Debrecen. Advantageous, moderately advantageous, moderately disadvantageous, and disadvantageous categories were established (Fig. 2).

Our study focused on the following issues:

- Is there a decrease or increase in the frequency of advantageous meteorological conditions (AMC) for the development of UHI?

- Is there a trend in the change of the frequency of advantageous conditions? 
Fig. 1 Location and position of Debrecen with the CarpatClim database grid points

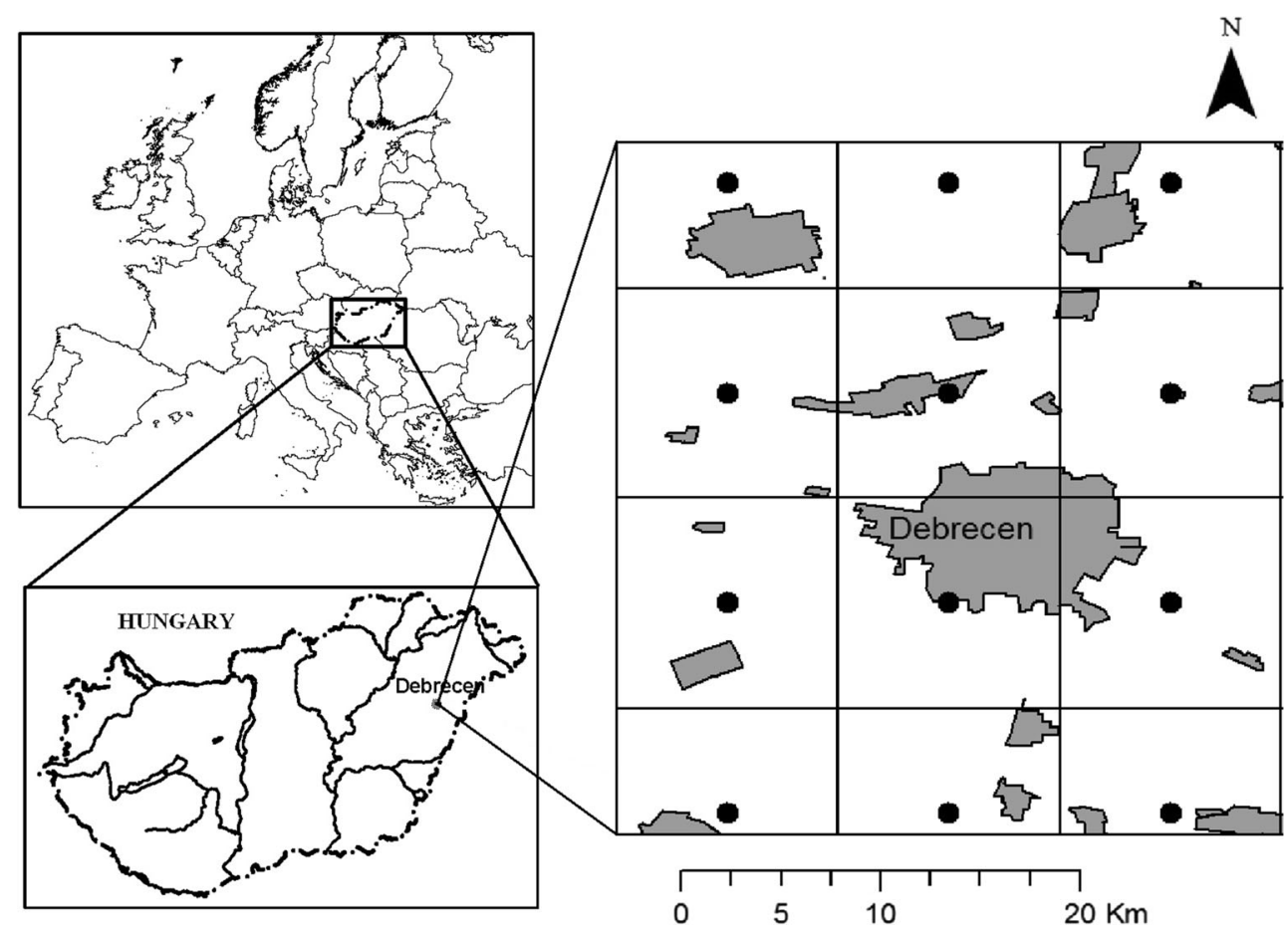

- Are there any change-points in the time series, dividing it into relatively homogeneous sections significantly different from each other?

\subsection{Methods}

\subsubsection{Correlation and trend analysis}

Null hypothesis of the trend analysis is that the distribution of the elements of the AMC time series is constant (stable). In order to identify any trends, the correlation between the elements of the data series and their No. in time is determined.
For this, parametric (Pearson) and non-parametric (Spearman and Mann-Kendall) correlation coefficients are available. Pearson's correlation coefficient is the most widespread:

$$
r=\frac{\sum\left(x_{i}-\bar{x}\right)\left(i-\frac{n+1}{2}\right)}{\sum(x-\bar{x})^{2} \sum\left(i-\frac{n+1}{2}\right)^{2}}
$$

where $x_{i}$ is the $i$ th element of the data set, $\bar{x}$ is the mean of the data set $i=1,2, \ldots, n$, and $n$ is the element number. Based on the obtained correlation coefficient and the element number,
Fig. 2 Frequency of UHI of condition categories, 1961-2010

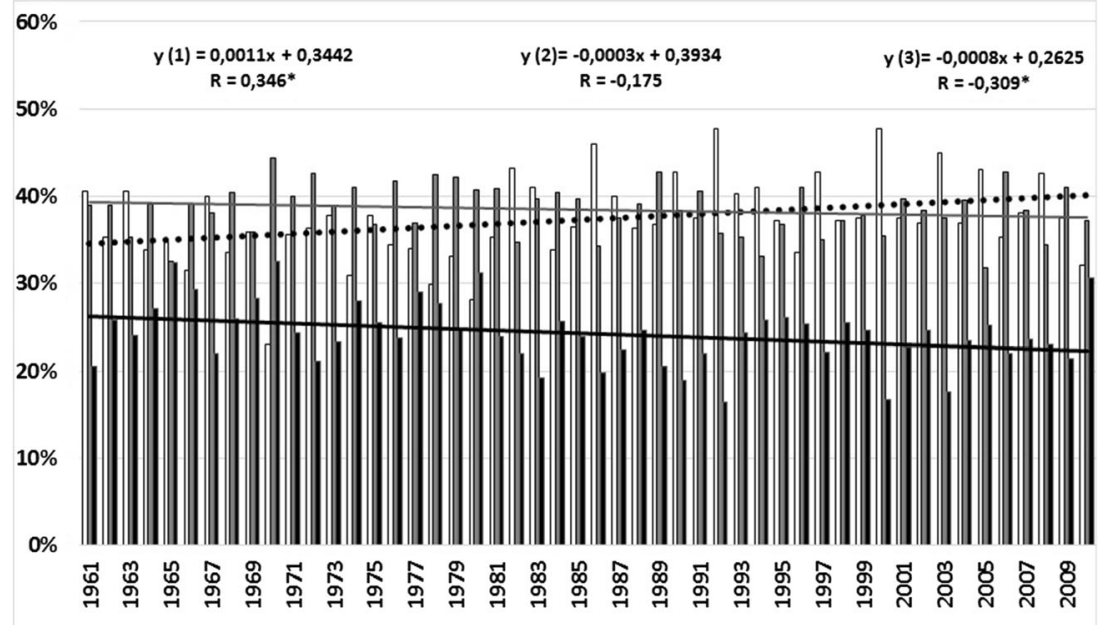

$\square$ Advantageous conditions (1)

$\square$ Moderately advantageous conditions (2)

- Disadvant ageous conditions (3) 
the reality of the correlation (trend in this case) can be decided using the appropriate table. This will decide whether the null hypothesis is true or false.

Spearman's correlation coefficient shows the strength of correlation between the rank of the time series elements $\left(z_{i}\right)$ in the sample with increasing order and their No. in the time series $(i)$.

$r_{S}=\frac{\sum\left(z_{i}-\frac{n+1}{2}\right)\left(i-\frac{n+1}{2}\right)}{\sqrt{\sum\left(z_{i}-\frac{n+1}{2}\right)^{2} \sum\left(i-\frac{n+1}{2}\right)^{2}}}$

Correlation statistics defined by Kendall and used for analyzing the time series can be calculated based on the element $\left(n_{i}\right)$ smaller than $x_{i}$ (Sneyers 1990):

$t=\sum n_{i}$

Distribution of $t$ values when the null hypothesis is true, i.e., the distribution is stable and when $n \geq 10$ is normal with the following parameters.

$\bar{t}=\frac{n(n-1)}{4}$

$\sigma^{2}=\frac{n(n-1)(2 n+5)}{72}$

where $\bar{t}$ is the mean, $\sigma^{2}$ is the variance, and $n$ is the element number.

If the correlation coefficient between the elements of the time series and their number together with the mean and standard deviation of the studied elements are known, the equation of the linear trend can be determined. This provides the most probable $x_{i}$ value of the $i$ element. The general form of the equation is:

$x_{i}=a i+b$

Constants can be calculated using the following formulae:

$a=r \frac{\sigma_{x}}{\sigma_{i}}$

$b=\bar{x}-a \bar{i}$

where $r$ is the correlation coefficient between the elements of the time series and their rank, $\sigma_{i}$ and $\bar{l}$ are the standard deviation and mean of the elements of the time series.
Multiplying the $b$ coefficient of the trend equations by the element number of the time series applied in the study provides the average value of the 50-year change.

Changes in the frequency of meteorological conditions for UHI development were approached by trend analysis (method of least squares) suitable for solving such problems. Correlations were calculated between elements of the time series and their temporal sequential numbers in order to reveal trends. Parametric and non-parametric correlations were applied as well. Parametric correlation requires normal distribution of the probability variable, while it is not a premise in the case of non-parametric correlations. Reality of increasing trends was judged on the basis of required correlation coefficients for given numbers of elements presented in a Table of Yule and Kendall (1950).

\subsubsection{Change-point analysis}

There are several methods for change-point analysis in the literature. In this study, the comparison of partial means was applied using Student's $t$ test. This method is based on the difference of means of periods separated at the date of a significant change is greater than that of periods separated at different dates. Comparison of the annual means was performed using the $t$ value (Péczely 1979).

$$
t=\frac{\overline{x_{1}}-\overline{x_{2}}}{S \sqrt{\frac{1}{n_{1}}+\frac{1}{n_{2}}}}
$$

where $\overline{x_{1}}$ and $\overline{x_{2}}$ are the means of the two periods, $n_{1}$ and $n_{2}$ are the element ranks, the number of years in the partial periods, $S$ is the joint standard deviation of the two samples that can be calculated using the following equation if the $\sigma_{1}$ and $\sigma_{2}$ standard deviation and the element number of the samples are known:

$S=\sqrt{\frac{\left(n_{1}-1\right) \sigma_{1}^{2}+\left(n_{2}-1\right) \sigma_{2}^{2}}{n_{1}+n_{2}-2}}$

Note that $t$ test can only be applied if the samples are normally distributed. Based on the Kolmogorov-Smirnov test, the annual distribution of advantageous conditions over the studied period did not differ significantly from normal. During the procedure, the time series of the annual \% values were divided into two sections of changing length by shifting the point of separation. Length of the sections was minimized in 5 years. The $t$ values used for Student's $t$ test were calculated for the means of the two sections. Following this, the point of separation was shifted forward step-by-step in time 
changing in this way the length of the two periods. Their means were compared at every step by determining the $t$ values. Considering the obtained $t$ values, the largest one indicates the greatest difference of the means of the two periods belonging to it, therefore this $t$ value can be regarded as the change-point. If a particular $t$ value at the associated degree of freedom (48 in this study) at a level of $95 \%$ indicated significant difference between the means of the sections, the change-point associated with the $t$ value was regarded to be a significant change-point. In order to identify further changepoints, the study was performed on the obtained partial periods as well (Molnár 2003; Sneyers 1990)

Identification of change-points in practice is illustrated in Fig. 5. The $t$ value reaches its maximum at the year 1982 and as its value is significant at the desired level, the turn of 1981 and 1982 is a significant change-point.

Beyond trend analysis, change-points were traced in the time series of different meteorological conditions of UHI development using Student's $t$ test (Yule and Kendall 1950; Sneyers 1990).

\subsubsection{Specifying the character of the changes}

The study involved the identification of linear trends and their change-points in the 50-year climatological time series of the frequency of advantageous conditions for UHI development. To decide which method describes the changes better, in other words, changes are gradual, or they take place by abrupt change, the method of sum of squared differences was used (Ward and Wendell 1980; Wayne 2000).

For this reason, $x_{t i}$ values of the trend line of the time series for years $i=1,2, \ldots, n$ were determined first; then, they were extracted from the $x_{i}$ values of each year (Eq. 11). The $S_{\text {tr }}$ value obtained by adding the squared differences describes the correctness of the fit of the trend line: lower values refer to better fit.

$S_{\mathrm{tr}}=\sum_{i=1}^{n}\left(x_{i}-x_{\mathrm{ti}}\right)^{2}$

In the next step, average values $\left(\bar{x}_{1}\right.$ and $\left.\bar{x}_{2}\right)$ of the two sections divided by the most emphasized change-point in the time series (Eq. 12) between $k$ and $k+1$ were determined by calculating sums of squared differences of values of each year taken from appropriate partial averages:

$S_{\mathrm{tp}}=\sum_{l=1}^{k}\left(x_{l}-\bar{x}_{1}\right)^{2}+\sum_{m=k+1}^{n}\left(x_{m}-\bar{x}_{2}\right)^{2}$

Where $x_{l}$ are values of the first section divided by the change-point for years $l=1,2 \ldots k, x_{m}$ are values of the second section for years $m=k+1, k+2, \ldots, n$.
Lower values of squared differences refer to a better fit. For comparison of correctness of fit ratio (Eq. 13) of the two squared difference values was used:

$g=\frac{S_{\mathrm{tr}}}{S_{\mathrm{tp}}}$

If $g<1$, linear trend fits better; if $g>1$, averages divided by the change-point fit better.

\section{Results}

3.1 Occurrence frequency of condition categories of UHI development

Synoptic conditions have a special annual course in the region of Debrecen which has a strong effect on the development of the UHI in the city. January and February is ruled by the Siberian high pressure system usually. Frontal activity connected to low pressure systems formed over the North Atlantic is strong from March to June, which causes a windy and rainy spring. High pressure systems formed over the Mediterranean seas or the Carpathian Basin govern the weather from July to mid October. The weather of the last months of the year is ruled by Cyclones formed over the North Atlantic or the Mediterranean seas. For this reason, the period between the midsummer and autumn provides the most favorable conditions for UHI development, while the weather of the spring and late autumn/early winter do not support the formation of strong heat islands. However, it must be noted that high annual variability is one of the most important characteristics of weather in the Carpathian Basin, so some years can be quite different from this scheme.

Occurrence frequency of condition categories regarding UHI development were the following during the study period:

- Advantageous conditions (category 1 AMC) $37.35 \%$, when there were no obstructive factors. Maximal development of UHI is possible in such cases.

- Moderately advantageous conditions (category $2 \mathrm{MMC}$ ) $38.46 \%$, when one obstructive factor for UHI formation is present. Medium or low intensity heat islands can develop under such circumstances.

- Moderately disadvantageous conditions (category 3) $20.88 \%$, when two obstructive factors appear making the development of only weak heat islands possible, or UHI cannot form.

- Disadvantageous conditions (category 4) $3.32 \%$, when there are three obstructive factors, preventing the development of the thermal excess in the settlements. 
It seemed reasonable to unify categories 3 and 4 (DMC) since the frequency of the latter one was very low, and their effect on UHI development was proven to be quite similar. Conditions are advantageous or at least moderately advantageous for UHI development in about $75 \%$ of all cases. This pattern can be explained by that high-pressure systems with favorable conditions tend to stay 6-7 days on the average over the Carpathian Basin, while warm and cold fronts of cyclones passes over our region in 1-2 days time.

\subsection{Trends and anomalies of the frequency of AMC}

Linear trend analysis has revealed a significant increasing trend in the time series of advantageous conditions. The value of Pearson correlation coefficient exceeded 0.27 at a significance level of $95 \%$ (Fig. 2). Non-parametric Spearman's correlation coefficients $(0.28)$ were determined as well, and they also revealed significant trends. The linear model applied suggested an increase of the frequency of AMC by $4 \%$ during the period between 1961 and 2010. There was no significant decrease of frequency in the moderately advantageous category, while frequency of moderately disadvantageous and disadvantageous categories showed significant decreasing trends of $2.2 \%$ based on the linear equation applied.

Anomalies of the frequency of advantageous conditions (category 1) were determined for each year from the average of the study period.

It is clearly visible in Fig. 3 that the frequency of AMC is under the average between 1964 and 1980, while the period between 1981 and 2009 is dominated by positive anomalies. Negative anomalies are reflected in $1970(-15 \%)$ and 1979 $(-10 \%)$. A weaker negative anomaly appears in 2010 $(-5.3 \%)$. This can be explained by the extremely high amount of precipitation in those years. Positive anomalies of advantageous conditions are characteristic after 1981 with maxima greater than $10 \%$ in 1992 and 2000.
Increasing frequency of AMC was analyzed for the seasons as well. Months of each season were treated together. Spring and summer produced significant increasing trends of frequency of advantageous conditions. Increase is stronger in the summer, reaching $5.6 \%$, while it reached $3.8 \%$ in spring. Winter and autumn have shown no significant increase of frequency of advantageous conditions marked by low correlation coefficients (winter $R=0.25$, summer $R=-0.12$ ).

Occurrence frequency of advantageous conditions was analyzed month by month. Average minimum of occurrence frequency of AMC can be related to December with $19.3 \%$ while the maximum is associated with August with $59.9 \%$. The absolute maximum occurred in August 1992 with $93.5 \%$. The absolute minimum occurred in December 1970 and November 1978 with $0 \%$. These results are in accordance with the typical annual course of synoptic conditions described before.

There are both small and remarkable differences in the monthly pattern of the frequency of advantageous conditions (Fig. 4). Frequency of advantageous conditions fluctuates between 19 and $28 \%$ in the winter months with lowest anomalies in January (9\%) which can be the consequence of frequent anticyclone conditions in that month. Differences in frequency of advantageous conditions are low in the spring months with a minimum of $4 \%$ only. Highest differences in the frequency of AMC occur in the summer with $17 \%$. August is outstanding since highest frequency and highest anomalies were detected in that month. Highest frequency and anomalies in the 50-year time series occurred in September regarding the autumn months. Highest standard deviations occur in that month also.

Trends of monthly frequency of advantageous conditions for Debrecen were examined in the next step.

Monthly trends are not parallel to seasonal ones in every case. There is no increasing trend in the case of winter; however, February is characterized by an increasing trend at a level of $95 \%$. No increasing trends have been revealed in the
Fig. 3 Frequency anomalies of advantageous conditions, $\%$ 1961-2010

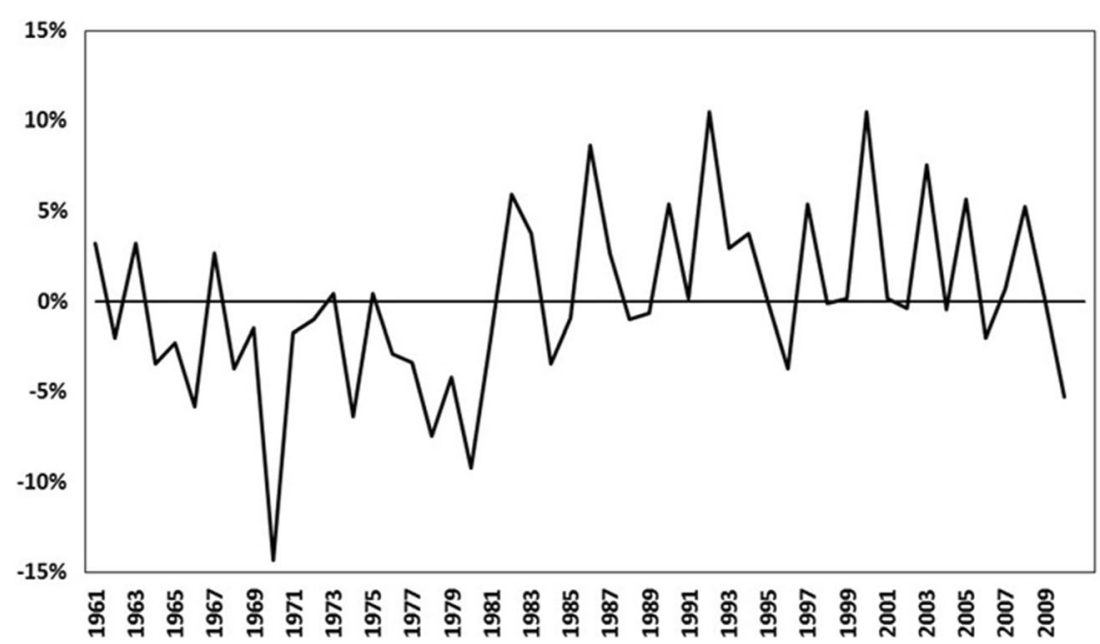


Fig. 4 Frequency of advantageous conditions, months, $\%, 1961-2010$

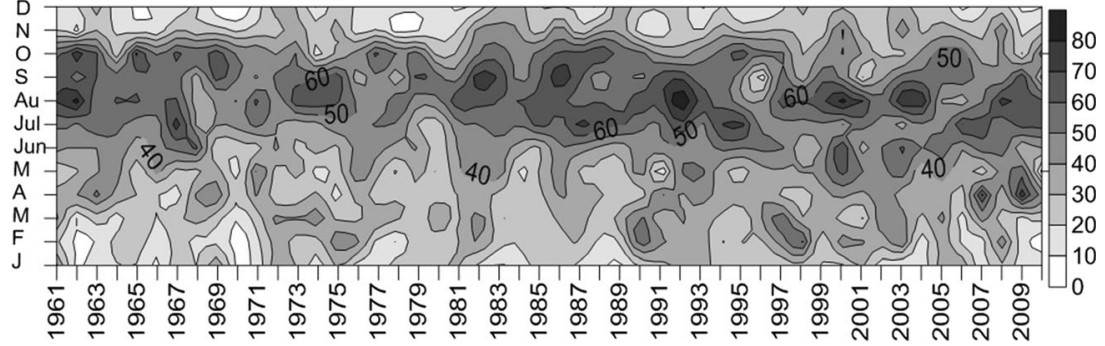

frequency of advantageous conditions in December and January as shown in Table 2.

Frequency showed a strong increasing trend in the case of spring. March and May are characterized by stagnation. Significant increase can be detected only in April. June produced a significant increase only from the summer months. Surprisingly, stagnation can be detected in the case of July and August as well. November seems to be more advantageous for UHI development; the other 2 months of autumn show stagnation.

It must be noted that values of Spearman's correlation coefficients support significances revealed by Pearson's $r$ values in the case of analyzing the monthly and seasonal time series.

\subsection{Detection of change-point in the time series}

Apart from trend analysis, change-point analysis was carried out on the time series. A significant change-point was found by Student's $t$ test at the turn of 1981/82 in the annual time series of advantageous conditions. Differences in partial averages separated by the change-point show an increase of over $5 \%$. Change-point analyses including seasonal frequency have detected significant change-points in each time series with the exception of autumn within the period between 1970 and 1990. Seasonal frequencies increased after the change-point. Strongest increase was detected in the case of summer ( $8 \%$ ) and spring (7\%), while a lower increase was found in winter $(4 \%)$, which is close to the annual average.

Change-points were detected in the time series of monthly average frequency of advantageous conditions by Student's $t$ test as well. Exceptions are January and February only. Differences in partial averages separated by the change-point showed rapid positive increases in most cases with values between 5 and $14 \%$. However, there were negative differences in September and October. The monthly change-point analysis revealed a temporal pattern similar to the annual ones.

Results presented above prove that there were significant changes in the frequency of conditions advantageous for UHI development in the region of Debrecen during the study period (Fig. 5). However, there are two possible interpretations of those results: changes can be either gradual or they can occur by abrupt change. To decide which interpretation is right, comparison of the squared differences was carried out.
Determination of $g$ values described in section 2.3 was carried out for annual frequency of conditions advantageous for UHI development. The fact that values higher than $1(g=$ 1.21) were found supports the discrete character of the process.

Analysis of seasonal averages showed similar results; however, $g$ values were lower than in the case of annual data. There was no increase in frequency of conditions advantageous for UHI development in autumn. Change-point analysis found significant increase of frequency only, meaning that increase took place by abrupt change. Highest $g$ values (1.18) were found in the summer datasets, and this refers to periodic increase. Spring has a character similar to that of summer from this aspect.

Table 2 Trend and change-point values of frequency of AMC in the period 1961-2010 for the years, seasons, and months

\begin{tabular}{lllll}
\hline Period & $R$ & $\begin{array}{l}\text { Trend } \\
\text { analysis }\end{array}$ & $\begin{array}{l}\text { Changing-point } \\
\text { test }\end{array}$ & $\begin{array}{l}\text { Increasing/ } \\
\text { decreasing }\end{array}$ \\
\hline Annual & $0.35^{* *}$ & + & $1981 / 82$ & $5 \%$ \\
Autumn & 0.25 & 0 & & \\
Spring & $0.39^{* *}$ & + & $1989 / 90$ & $7 \%$ \\
Summer & $0.36^{* *}$ & + & $1980 / 81$ & $8 \%$ \\
Winter & -0.12 & 0 & $1970,1981 / 82$ & $4 \%$ \\
January & 0.00 & 0 & & $14 \%$ \\
February & $0.28^{*}$ & + & $1971 / 72$ & $9 \%$ \\
March & 0.14 & 0 & 1971 & $11 \%$ \\
April & $0.33^{* *}$ & 0 & 1990 & $9 \%$ \\
May & 0.23 & 0 & 1991 & $10 \%$ \\
June & $0.32^{* *}$ & + & 1989 & $10 \%$ \\
July & 0.22 & 0 & 1982 & $5 \%$ \\
August & 0.13 & 0 & 1991 & $-11 \%$ \\
September & -0.21 & 0 & 1994 & $-9 \%$ \\
October & -0.25 & 0 & $1970 / 71,1997$ & $11 \%$ \\
November & $0.33^{* *}$ & + & $1981 / 82$ & \\
December & 0.13 & 0 & & \\
\hline
\end{tabular}

+ increasing trend, $O$ stagnating trend, - decreasing trend

${ }^{*} p<0.05,{ }^{* *} p<0.01$ 
Fig. 5 Trend and change-point analysis of conditions advantageous for UHI development, 1961-2010

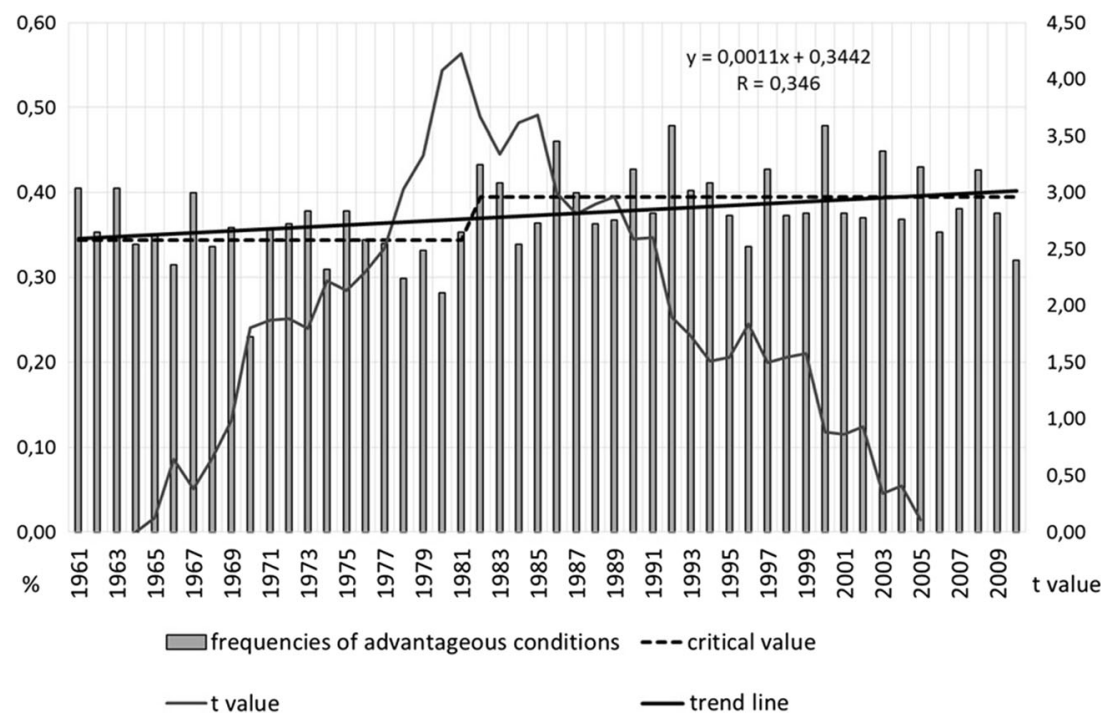

Trends and change-points were detected in the monthly data as well with $g$ values between 1.01 and 1.2 supporting periodic increase again.

The results our analyses can be associated with the abrupt change of the climate of the northern hemisphere and the Carpathian Basin at the turn of the 1970s and 1980s (Molnár 2003; Meyhöfer et al. 1996).

\section{Conclusions}

Four meteorological condition categories of UHI development were established using values of wind speed, cloudiness, and precipitation. Critical values were determined on the basis of data available in the literature and our previous UHI measurement campaigns. Frequencies of occurrence of condition categories of UHI development were determined. Advantageous and moderately advantageous conditions were found to be dominant in the time series: advantageous and moderately advantageous conditions for UHI development were found in more than $75 \%$, while unfavorable conditions were found in less than $25 \%$ of all cases.

A trend analysis was performed in order to decide if there is a tendency in the frequency of AMC. Linear trend analysis revealed a significant increasing trend in the time series of advantageous conditions. Increase of the frequencies of advantageous conditions were analyzed for the years, seasons, and months of the study period as well. Spring and summerespecially April and June-showed significant increasing trends of frequencies of advantageous conditions. Winter and autumn did not show increase of those frequencies. The only exception was February, when a significant increase took place.

Anomalies of the frequency of advantageous conditions were determined for each year from the average of the study period. The frequency of AMC is under the average between 1964 and 1980, while the period between 1981 and 2009 is dominated by positive anomalies. Negative anomalies of some years can be explained by the high amount of precipitation in those years.

Change-point analyses detected a significant increase in the frequency of advantageous conditions in the time series at the turn of 1981/1982. The change-point is emphasized in the summer and spring months.

Detected tendencies have negative effects on urban energy consumption: they contribute to the increase of air conditioning energy demand in the summer; however, they do not decrease the energy demand of heating in the winter significantly.

Acknowledgments The authors are grateful to anonymous reviewers for providing valuable comments on this study.

\section{References}

Arnfield A (2003) Two decades of urban climate research: a review of turbulence, exchanges of energy and water, and the urban heat island. Int J Climatol 23:1-26. doi:10.1002/joc.859

Bottyán Z, Unger J (2003) A multiple linear statistical model for estimating the mean maximum urban heat island. Theor Appl Climatol 75: 233-243. doi:10.1007/s00704-003-0735-7

Bottyán Z, Kircsi A, Szegedi S, Unger J (2005) The relationship between built-up areas and the spatial development of the mean maximum urban heat island in Debrecen, Hungary. Int J Climatol 25:405-418. doi:10.1002/joc. 1138

Chen et al (2011b) The integrated WRF/urban modelling system: development, evaluation, and applications to urban environmental problems. Int J Climatol 31:273-288. doi:10.1002/joc.2158

Eliasson I (1996) Urban nocturnal temperatures, street geometry and land use. Atmos Environ 30:379-392. doi:10.1016/1352-2310(95) 00033-X 
Eliasson I, Svensson MK (2003) Spatial air temperature variations and urban land use - a statistical approach. Meteorol Appl 10:135-149. doi: $10.1017 / \mathrm{S} 1350482703002056$

Ganbat G, Han J-Y, Ryu Y-H, Baik J-J (2013) Characteristics of the urban heat island in a highaltitude metropolitan city, Ulaanbaatar, Mongolia. Asia-Pac J Atmos Sci 49:535-541

Giannaros TM, Melas D, Daglis IA, Keramitsoglou I, Kourtidis K (2013) Numerical study of the urban heat island over Athens (Greece) with the WRF model. Atmos Environ 73:103-111. doi:10.1016/j. atmosenv.2013.02.055

JRC, 2010: Climate of the Carpathian Region. Technical Specifications (Contract Notice OJEU 2010/S 110-166082 dated 9 June 2010). http://desert.jrc.ec.europa.eu/action/php/index.php?action= view\&id $=550$. Accessed 12 August 2014

Kim YH, Baik JJ (2002) Maximum urban heat island intensity in Seoul. J Appl Meteorol 41:651-659

Klysik K, Fortuniak K (1999) Temporal and spatial characteristics of the urban heat island of Lodz. Poland Atmos Environ 33:3885-3895

Lakatos M, Szentimrey T, Bihari Z, Szalai S (2013) Creation of a homogenized climate database for the Carpathian region by applying the MASH procedure and the preliminary analysis of the data. Időjárás 117:143-158

Landsberg HE (1981) The Urban Climate. New York-London-TorontoSydney, San Francisco

Lee S-H, Baik J-J (2010) Statistical and dynamical characteristics of the urban heat island intensity in Seoul. Theor Appl Climatol 100:227237. doi:10.1007/s00704-009-0247-1

Loughner CP, Allen DJ, Zhang D-L, Pickering KE, Dickerson RR, Landry L (2012) Roles of urban tree canopy and buildings in urban heat island effects: parameterization and preliminary results. J Appl Meteorol Climatol 51:1775-1973. doi:10.1175/JAMC-D-11-0228. 1, DOI:10.1175/JAMC-D-11-0228.1\# blank\#Go to external source

Meyhöfer S, Rapp J, Schönwiese C-D (1996) Observed threedimensional climate trends in Europe 1961-1990. Meteorol Z NF 5:90-94

Molnár J (2003) The structure of the pressure field and its alteration in the surroundings of the Carpathian Basin (in Hungarian). Dissertation, University of Debrecen

Oke TR (1973) City size and the urban heat island. Atmos Environ 7: 769-779. doi:10.1016/0004-6981(73)90140-6

Oke TR (1987) Boundary layer climates. Routledge, London-New York

Orlanski I (1975) A rational subdivision of scales for atmospheric processes. Bull Am Meteorol Soc 56:527-530
Péczely G (1979) Climatology (in Hungarian), Budapest: pp 336

Sneyers S (1990) On the statistical analysis of series of observations. Technical note no. 5 143, WMO No 725 415, Secretariat of the World Meteorological Organization, Geneva

Spinoni et al (2014) Climate of the Carpathian Region in the period 1961-2010: climatologies and trends of 10 variables. Int J Climatol. doi:10.1002/joc.4059

Szegedi S, Kircsi A (2003) The development of the urban heat island under various weather conditions in Debrecen, Hungary. Proceed ICUC-5, Lodz, Poland 1:139-142

Szegedi S, Tóth T, Kapocska L, Gyarmati R (2013) Examinations on the factors of urban heat island development in small and medium-sized towns in Hungary. Carpathian J Earth Environ Sci 8:209-214

Szentimrey T (2011) Manual of homogenization software MASHv3.03. Hungarian Meteorological Service, 66

Szentimrey T, Bihari Z (2006) MISH (Meteorological Interpolation based on Surface Homogenized Data Basis), COST Action 719 Final Report, The use of GIS in climatology and meteorology, Edited by Ole Einar Tveito, Martin Wegehenkel, Frans van der Wel and Hartwig Dobesch, 54-56

Szymanowski M (2005) Interactions between thermal advection in frontal zones and the urban heat island of Wroclaw, Poland. Theor Appl Climatol 82:207-224

Unger J (1996) Heat island intensity with different meteorological conditions in a medium-sized town: Szeged, Hungary. Theor Appl Climatol 54:147-151

Unger J, Bottyán Z, Sümeghy Z, Gulyás A (2000) Urban heat island development affected by urban surface factors. Időjárás 104:253-268

Unger J, Bottyán Z, Sümeghy Z, Gulyás A (2004) Connection between urban heat island and surface parameters: measurements and modeling. Időjárás 108:173-194

Ward JE, Wendell RE (1980) A new norm for measuring distance which yields linear location models. Oper Res 28:836-844

Wayne TW (2000) Change-point analysis: a powerful new tool for detecting changes. http://www.variation.com/cpa/tech/changepoint. html. Submitted to Quality Engineering. Accessed 12 October 2014

Wilby RL (2003) Past and projected trends in London's urban heat island. Weather 58:251-260

Wilby RL (2008) Constructing climate change scenarios of urban heat island intensity and air quality. Environ Plan B: Plan Des 35:902919

Yule GU, Kendall MG (1950) An introduction to the theory of statistics. London. http://www.carpatclim-eu.org/pages/about/ 